\title{
Empirical Estimation of Ethanol-Methylcellulose based Green Gel Propellant Viscosity at Varying Temperature
}

\author{
Saugata Mandal ${ }^{1}$, Balaguru Pandian ${ }^{*}, 2$ and Rajarshi Das ${ }^{3}$ \\ ${ }^{1}$ Teaching Assistant, Gas Dynamics and Propulsion Laboratory, School of Mechanical \\ Engineering, SASTRA Deemed to be University, Thanjavur, Tamil Nadu, 613401. India. \\ 2, * Research Assistant, Gas Dynamics and Propulsion Laboratory, School of Mechanical \\ Engineering, SASTRA Deemed to be University, Thanjavur, Tamil Nadu, 613401. India. \\ ${ }^{3}$ Senior Assistant Professor, Gas Dynamics and Propulsion Laboratory, School of Mechanical \\ Engineering, SASTRA Deemed to be University, Thanjavur, Tamil Nadu, 613401. India. \\ ${ }^{1}$ E-mail: samthetoon@gmail.com \\ 2, *E-mail: balaguru@ sastra.ac.in \\ ${ }^{3}$ E-mail: rajarshidas@mech.sastra.edu \\ DOI: $10.51201 / J U S S T / 21 / 07323$
}

\begin{abstract}
The rheological behavior of the Ethanol based green gels for use in propulsion systems at temperature range of $10^{\circ} \mathrm{C}-50^{\circ} \mathrm{C}$ is investigated by employing a novel empirical model developed. The study is conducted at various shear rates. Empirically predicted results were observed to be in good agreement with experimental data at higher shear rates for both pure and energized gel system (>100 $\left.\mathrm{s}^{-1}\right)$. Considering the results, the present empirical model is deemed suitable for those Non-Newtonian shear thinning fluids which obey Power law.
\end{abstract}

Keywords: Green gel propellant, Gel rheology, Apparent viscosity-temperature correlation, Power law, Loaded and unloaded ethanol gel propellant

\section{Introduction}

The combined requirement of high performance and safe handling of propellants for rocket engine has significantly increased since last few decades as stated by Schindler R.C. et. al. [1]. Gelling of the high performing liquid propellants provides a suitable solution to address this requirement. According to Brinker C.J. et.al. [2] gel contains a continuous solid skeleton enclosing a continuous liquid phase, the continuity of the solid structure providing elasticity for the gel. In rheological terms, it is known to have viscoelastic properties.

Due to its viscoelastic nature, gel propellants combine advantages of both liquid (performance- physical and chemical) and solid (storability and safety) propellants. Disadvantages of liquid propellants such as sensitivity towards impact, friction, sloshing, electrostatic discharge, spills/leaks, volatility and accidental ignition are significantly eradicated in case of gel propellants. Comparatively low vapor pressure at standard temperature and pressure (STP) for gel propellants ensures better storability by reducing chances of undesirable tank pressure, as per the study conducted by Pinto P. C. et.al. [3]. Prior study by Naumann K.W. et.al. [4] concluded that comparable specific impulse $\left(\mathrm{I}_{\mathrm{sp}}\right)$ or density specific impulse can be achieved by adding metal additives thus making it an attractive alternative for standard propellants. It can hold its consistency for long periods as well, thus preventing sedimentation and amalgamation of solid additives.

The viscoelastic property of gels has significant effect on pressurized flow (through pipe) from tank to injector. Shear thinning fluids have plug flow velocity profile with lower velocities at the centerline and high gradient near the channel wall. A flow region with a constant velocity in a particular area (near to channel axis) along the channel cross section occurs, which is due to shear stresses being lower than the yield stress of the fluid. The size of this plug flow region depends on the ratio of the yield stress to the shear stress at the wall $\left(\tau_{\mathrm{y}} / \tau_{\mathrm{w}}\right)$. For lower $\left(\tau_{\mathrm{y}} / \tau_{\mathrm{w}}\right)$ or higher average velocity, the plug flow region gets smaller. This distinct flow behavior has to be considered for the design of feed pipes, injector and valves as it also affects the heat transfer and heat transport properties, as observed by Ciezki H. K. et. al. [5]. 
Canino J. et.al. [6] stated that viscoelastic properties also influence velocity profile and boundary layer thickness at the orifice exit plane of a gel injector thereby affecting atomization of gels. Chojnacki K. [7] observed that inside the injector, Reynolds number and viscoelastic nature of gels guide the development of appropriate boundary layer which controls the jet behavior. Due to its viscoelastic nature, gels require sophisticated and bulky flow control systems. Formation of jets and atomization of gels is more challenging; hence combustion of gels is slower, relatively, as per Heister S. [8]. Thus, high efficiency of gel propulsion systems is not yet conceivable, though during operation high throttling capability of such systems makes it possible to increase the flight range of missile systems by effective energy management [1].

Viscoelastic/atomization phenomena of gel propellants have been studied experimentally extensively during the previous decades by Ferguson, J. and Kemblowski, Z. [10], Chojnacki K., [7], by Rahimi S. and Natan B. [8], by Canino J. and Heister S. [6], by Heister S. et.al. [8] and by Jyoti B.V.S. and Baek S.W. [11]. However, reports on development of robust empirical model to estimate the viscosity of the non-Newtonian fluid as a function of temperature is still scarce in current available literature. To fill in this particular gap, an attempt has been made to arrive at an empirical model predicting the viscoelastic nature of green gel-based propellants over a range of temperature and shear stresses.

\section{Nomenclature}

$\begin{array}{ll}\eta & \text { Apparent viscosity } \\ \mathrm{k} & \text { Consistency index } \\ \gamma & \text { Shear rate } \\ \mathrm{n} & \text { Power index } \\ \mathrm{T} & \text { Temperature } \\ \tau & \text { Shear stress } \\ \mathrm{ex} & \text { Experimental } \\ \text { th } & \text { Empirically calculated } \\ \mathrm{MW} & \text { Molecular weight }\end{array}$

\section{Subscripts}

$\begin{array}{ll}0 & \text { reference/initial } \\ 1 & \text { other/unknown } \\ \mathrm{w} & \text { wall } \\ \mathrm{y} & \text { yield }\end{array}$

\section{Empirical Model}

Several mathematical models are available to define apparent viscosity behavior for nonNewtonian fluids. The Power law [10] is the simplest and most widely used model to determine the shear rate dependent apparent viscosity relation for many non-Newtonian thixotropic time-dependent fluids, which is given by

$\eta=K \gamma^{(n-1)}$

where $\eta, K, \gamma$ and $n$ are the apparent viscosity, consistency index (constant), shear rate and power-index respectively. As stated by Natan B. and Rahimi S. [12], the shear thinning range of index " $\mathrm{n}$ " is $0<\mathrm{n}<1$ for gels. Also, most of the gel propellants obey Power law, display shear thinning properties and are thixotropic (Natan B. and Rahimi S. [13]) in nature. 
It has been observed by Cornelissen J. and Waterman H.I. [14] that for liquids, exponential model is suitable for viscosity-temperature correlation. Thus, similar approach is implemented in this work, as gels are basically obtained from pure liquid (solvent) by adding gelling agent (gellant) where the gellant mass fraction is often very low. The procedure adopted to arrive at such a relation for gel propellants is presented as a flow chart in Fig 1. Experimental data of previous researches [15] were acquired, from which reference parameters for this empirical evaluation are calculated. Reference parameters are temperature $T_{0}$, and apparent viscosity $\eta_{0}$. To determine the apparent viscosity $\eta_{\mathrm{T}}$ at any temperature $\mathrm{T}$ from the reference conditions, Power law is modified by adding the exponential temperature "factor" $e^{\frac{T_{0}}{T}}$, yielding the general modified equation as

$\eta_{T}=K \gamma^{(n-1)} \cdot e^{\frac{T_{0}}{T}}$

where " $\mathrm{K}$ " and " $\mathrm{n}$ " are consistency index and power index respectively of the reference data.

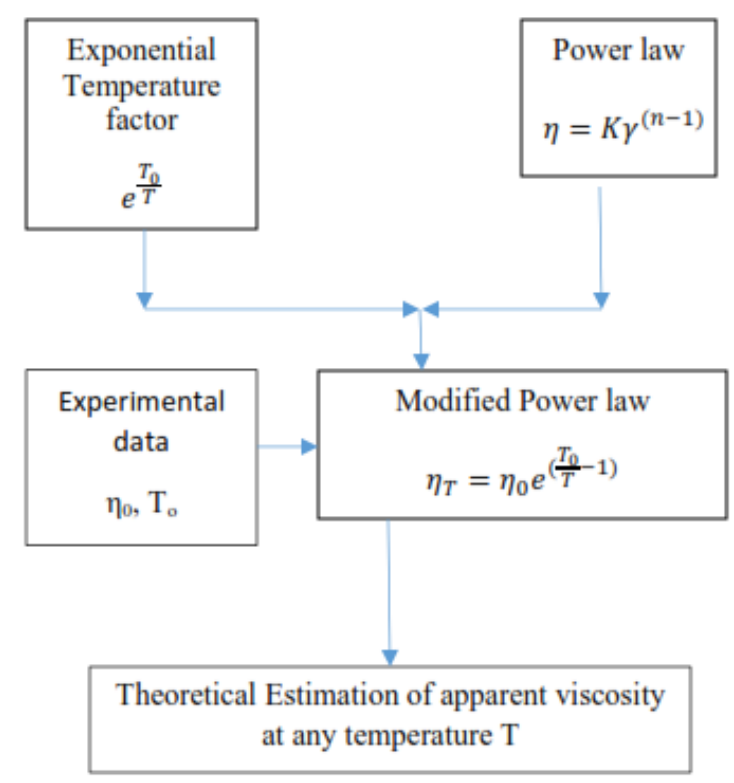

Figure 2.1. Flow chart for determination of modified Power law model

The reason for considering the exponential factor $e^{\frac{T_{0}}{T}}$ is because it is consistent with the fact that as the temperature increases, the apparent viscosity decreases and vice versa. The exponential nature of the factor is additionally suitable for logarithmic plotting and extrapolation of such curves. From this modified Power law and by substituting $\mathrm{T}=\mathrm{T}_{0}$, at reference condition, apparent viscosity is given by

$\eta_{0}=K \gamma^{(n-1)} \cdot e$

For any other temperature $\mathrm{T}=\mathrm{T}_{1}$, from Eq. 2 we get

$\eta_{T_{1}}=K \gamma^{(n-1)} \cdot e^{\frac{T_{0}}{T_{1}}}$

Here, $\mathrm{K}$ and $\mathrm{n}$ value in Eq.3 and Eq.4 remains same because to determine $\eta_{T_{1}}$ at $\mathrm{T}_{1}$, reference value is $\eta_{0}$. Dividing Eq. (4) with Eq. (3) we get

$\eta_{T_{1}}=\eta_{0} e^{\left(\frac{T_{0}}{T_{1}}-1\right)}$

For a particular gel, to obtain the reference $\eta_{0}$ and $\mathrm{T}_{0}$, arithmetic mean of apparent viscosity and temperature is calculated from the experimental data. For instance, available experimental data of a particular gel within the temperature range of $283 \mathrm{~K}-323 \mathrm{~K}$ will have a $\mathrm{T}_{0}$ of $303 \mathrm{~K}$. The apparent viscosities at various temperatures (say at increment of $10 \mathrm{~K})$ is considered and the mean is calculated which will provide values for $\eta_{0}$ at a 
particular shear rate. Thus, by substituting these values in Eq. (5) an empirically calculated values for that particular gel can be determined at any desired temperature at that particular shear rate. Propellants considered for this investigation are Ethanol-Methylcellulose based gels. The reason to investigate Ethanol-Methylcellulose based gels for rocket propellants is because it comes under the category of 'green propellants. Further, the addition of widely used metal additives like aluminium and boron particles improves the efficiency of such propellants due to their high heat of combustion and lower atomic weight.

A brief description of the gel preparation is mentioned here, further details can be found in Joyti et. al. [15]. Ethanol is the base fuel, and aluminium and boron nanoparticles were selected for the metallized ethanol gel system. The average particles diameters of $\mathrm{Al}(99.9 \%$ pure) and B (97\% pure) are 50nm and 290nm, respectively. The critical concentrations of gellant were determined as $8 \%$ and $9 \%$ (by wt.) for non-metalized gel and $4 \%$ and $6 \%$ (by wt.) for Al and B metalized gel, respectively. The gelling agent (Methylcellulose (MC): MW 40,000) which is used for the gelation process is compatible and nonreactive with ethanol.

Initially dispersions of methylcellulose particles in an ethanol fuel-water mixture were prepared by mixing the ingredients thoroughly for 15 minutes at room temperature $(298.15 \mathrm{~K} \pm 1 \mathrm{~K})$ by stirring with a three-blade laboratory impeller at 3,000 rpm. The suspension was stirred thoroughly to ensure complete dissolution of the gellant in the fuelwater mixture. To prepare the metallized ethanol gel, metal particles were added after thoroughly mixing the gellant, and the suspension was stirred thoroughly again to completely dissolve the gellant and incorporate the aluminium/boron metal particles in the fuel. The mixture was then left undisturbed to allow the network to form. The process details were maintained same for all the preparations.

Table 1. Gel propellants used for the investigation

\begin{tabular}{|c|c|}
\hline Gel & Gellant \% (by wt.) \\
\hline Ethanol-Methylcellulose & 8 \\
\hline Ethanol-Methylcellulose $+20 \%$ Aluminium (by wt.) & 4 \\
\hline Ethanol-Methylcellulose $+20 \%$ Boron (by wt.) & 6 \\
\hline
\end{tabular}

The composition of each propellant is illustrated in Table 1. The rheological behavior of each of these propellants at different shear rate $\left(1-1000 \mathrm{~s}^{-1}\right)$ was analyzed at different temperatures between the range of $283.15 \mathrm{~K}-323.15 \mathrm{~K}$.

\section{Results and discussion}

To validate the estimation procedure visualized in Figure 2.1., variation of calculated values by empirical correlation mentioned and experimental data at different temperatures for the gels are shown in Figure 3.1, Figure 3.2, Figure 3.3, Figure 3.4, Figure 3.5 and Figure 3.6. The variations are plotted in log-linear graph to emphasize the deviation from corresponding experimental value. Figure 3.1 and Figure 3.2 show the comparison between empirically calculated values (th) values and experimental (ex) data of Ethanol-Methyl Cellulose (8\%) [Et-MC] gel at different temperatures. It is observed from Figure 3.1 and Figure 3.2 that the calculated values are approximately same as experimental data for shear rates of $\sim 90 \mathrm{~s}^{-1}$ and above at all the temperatures. 


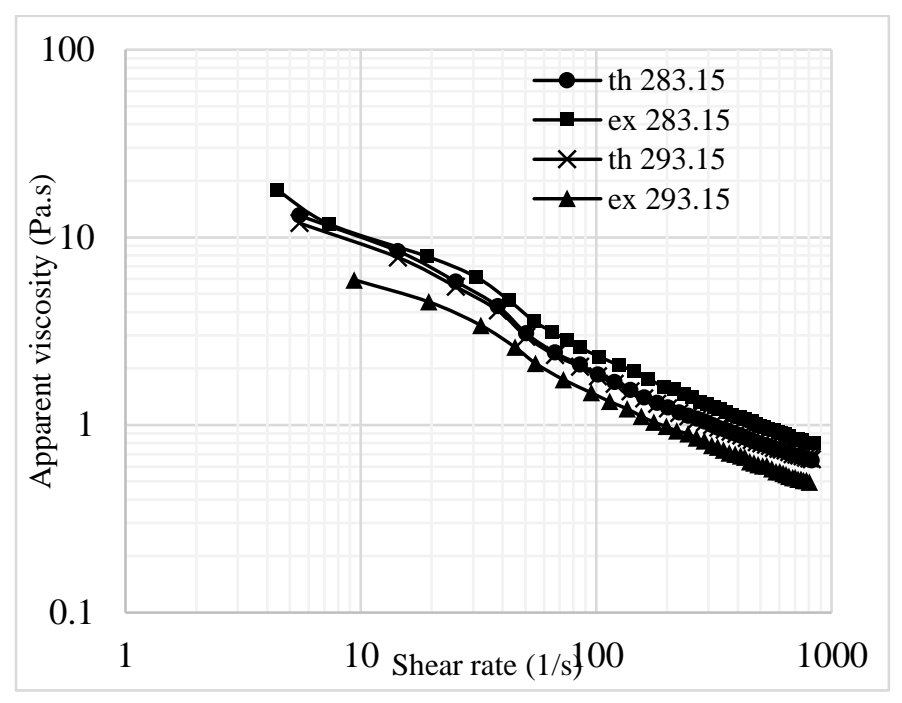

Figure 3.1. Variation of $\eta$ for Ethanol-Methyl Cellulose (8\%) gel

For this particular gel, maximum deviation in estimation of apparent viscosity is approximately 5Pa.s (approx. at $5 \mathrm{~s}^{-1}$ and $283.15 \mathrm{~K}$ ) from the experimental values at any given shear rate at all the different temperatures investigated. However, it is distinctly visible that the initial $\eta$ values for shear rate less than $90 \mathrm{~s}^{-1}$ are different for calculated values and experimental data.

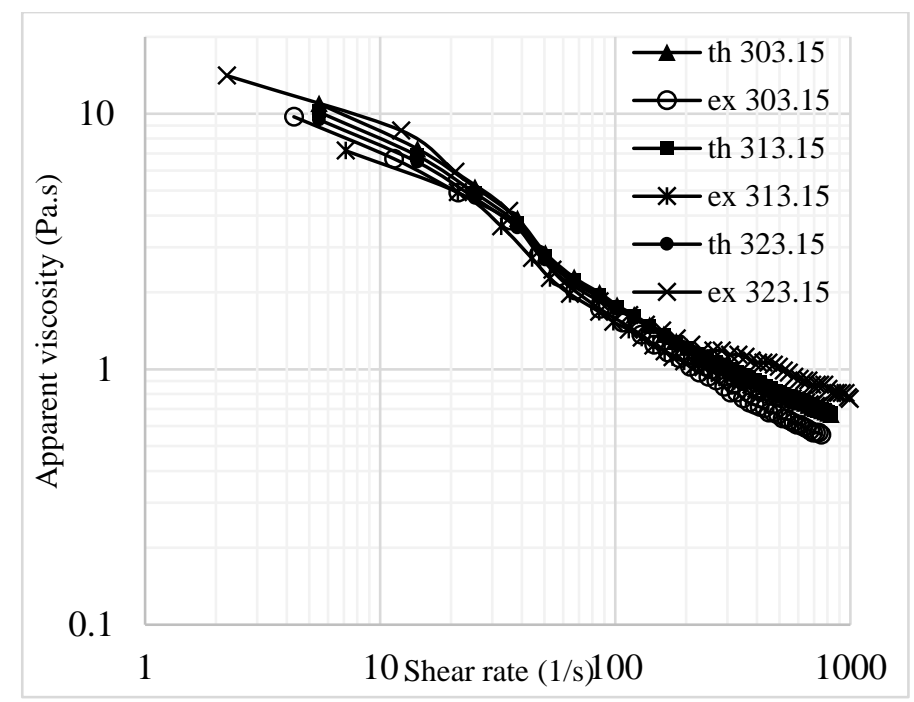

Figure 3.2. Variation of $\eta$ for Ethanol-Methyl Cellulose (8\%) gel

This may be due to curve fitting parameters employed while digitalizing the experimental data. Apparent viscosity values beyond this range of shear rate can be extrapolated by this empirical relation by curve fitting method with satisfactory approximation. At higher shear rates $\left(>90 \mathrm{~s}^{-1}\right)$ the gel shows more fluidity and the apparent viscosity (calculated and experimental values) becomes almost identical within the given temperature range. 


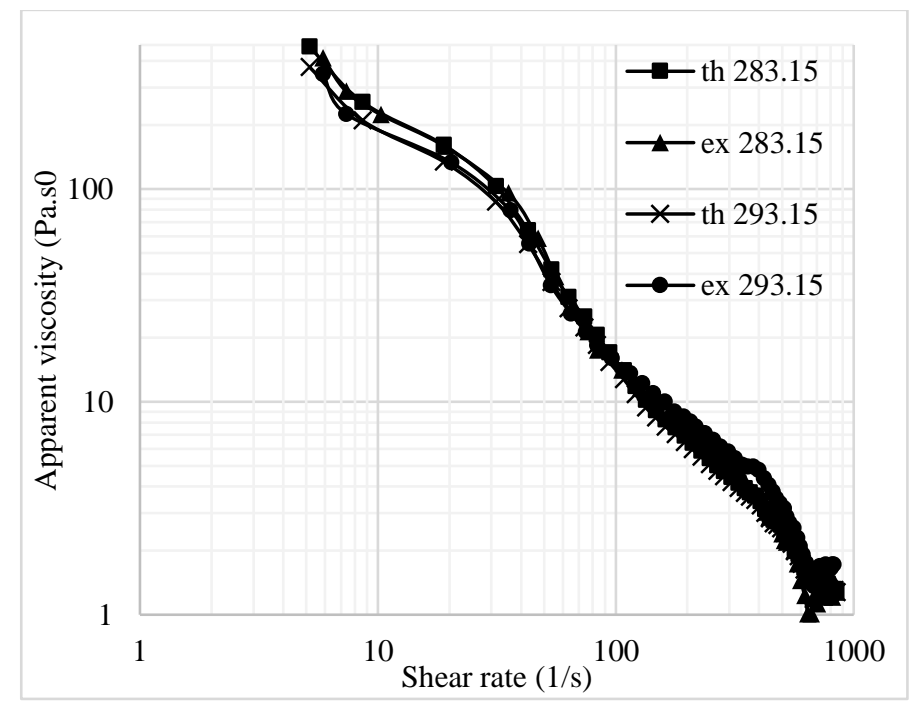

Figure 3.3. Variation of $\eta$ for Ethanol-Methyl Cellulose (4\%) $+\mathrm{Al}(20 \%)$ gel

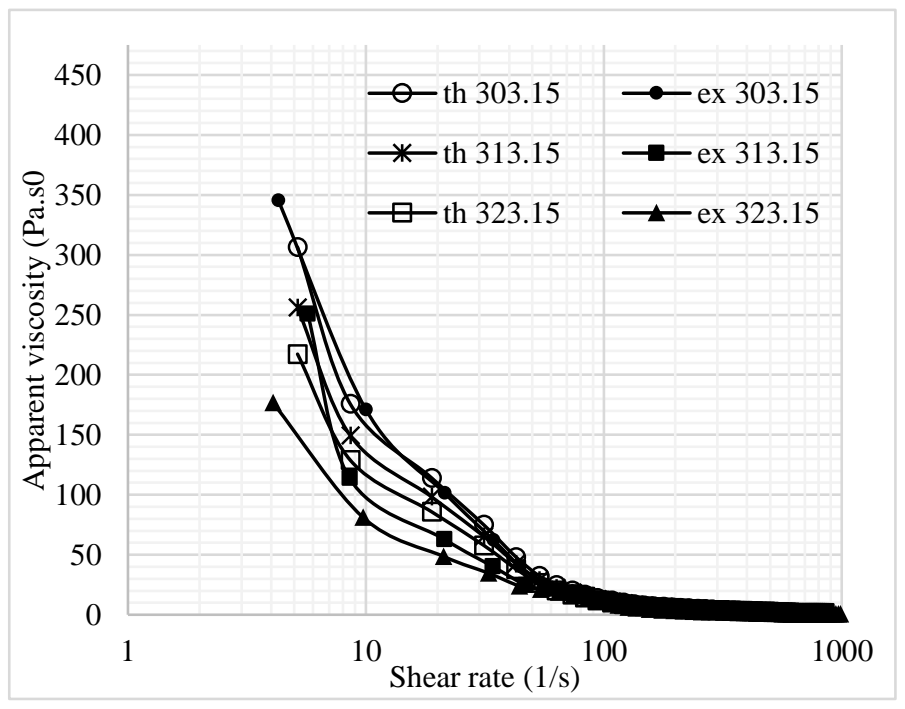

Figure 3.4. Variation of $\eta$ for Ethanol-Methyl Cellulose (4\%) $+\mathrm{Al}(20 \%)$ gel

Figure 3.3 and Figure 3.4 show the $\eta$ variation of Ethanol-Methyl Cellulose $(4 \%)+$ Aluminium (20\%) [Et-MC + Al] gel at the same temperatures and shear rate range. For this case, empirically calculated values are in good agreement with experimental data except for the cases at temperatures $313.15 \mathrm{~K}$ and $323.15 \mathrm{~K}$, where the deviation is marginally higher at shear rates of less than $90 \mathrm{~s}^{-1}$. The maximum deviation is approximately $40 \mathrm{~Pa} . \mathrm{s}$ (approx. $4 \mathrm{~s}^{-1}$ and $323.15 \mathrm{~K}$ ). And as mentioned before, by extrapolation $\eta$ can be determined approximately within this deviation margin. 


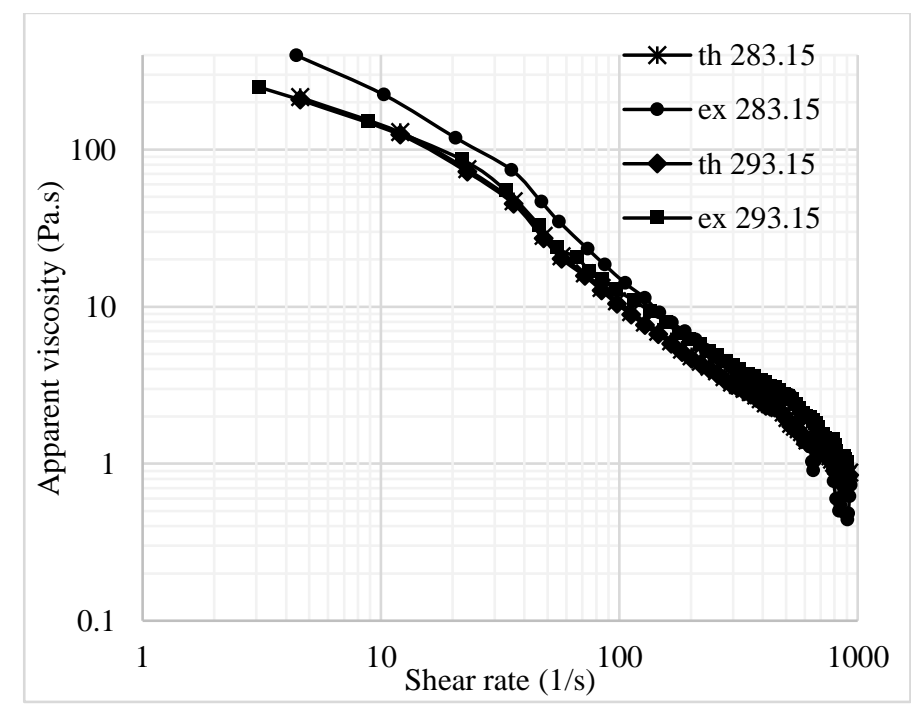

Figure 3.5. Variation of $\eta$ for Ethanol-Methyl Cellulose (6\%) + B (20\%) gel

Figure 3.5. and Figure 3.6 show the comparison between empirically calculated values and experimental data of Ethanol-Methyl Cellulose (4\%) + Boron (20\%) gel [Et-MC + B]. The apparent viscosity is in the range of $0.4-400$ Pa.s.

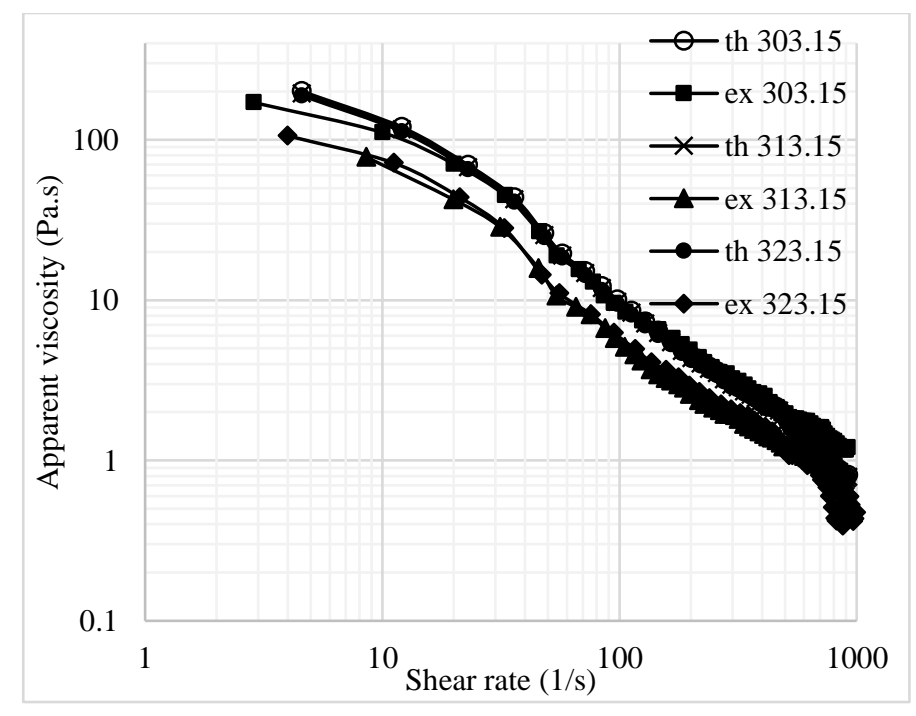

Figure 3.6. Variation of $\eta$ for Ethanol-Methyl Cellulose $(6 \%)+B(20 \%)$ gel

For this case also, empirically calculated values are significantly higher than experimental values at all the temperatures except for the case of $283.15 \mathrm{~K}$ and $293.15 \mathrm{~K}$ for low shear rate values $\left(<90 \mathrm{~s}^{-1}\right)$ only. The maximum deviation for the Ethanol-Methyl Cellulose $(6 \%)$ $+\mathrm{B}(20 \%)$ gel at $283.15 \mathrm{~K}$ is approximately $180 \mathrm{~Pa}$.s (at $\left.4.5 \mathrm{~s}^{-1}\right)$. Here margin of deviation for the case at $283.15 \mathrm{~K}$ for lower shear rates $\left(<5 \mathrm{~s}^{-1}\right)$ is observed to be around 500Pa.s by extrapolating the data. However, this needs to be verified experimentally. From the above observations it can be said that at higher shear rate (approx. 100s-1 and above), values of apparent viscosity begin to merge together. For further increase in shear rate $\left(>1000 \mathrm{~s}^{-1}\right)$, decrease in apparent viscosity is obvious until it reaches lower Newtonian plateau. This is required to be determined experimentally for all the gels, which can be expected to attain higher shear rates of $10000 \mathrm{~s}^{-1}$ or more which are also observed by Madlener K. and Ciezki H. K. [16]. 
Figure 3.7 shows the variation of consistency index ' $\mathrm{K}$ ' and power index ' $\mathrm{n}$ ' with temperature for all the three gels. The x-axis represents temperature and primary $y$-axis (left) and secondary y-axis (right) is ' $K$ ' and ' $n$ ' respectively. The ' $K$ ' and ' $n$ ' values are obtained for each gel, at each temperature, for the shear rate range of $1-1000 \mathrm{~s}^{-1}$. For the Et$\mathrm{MC}$ gel, ' $\mathrm{K}$ ' values are almost linearly decreasing and ' $\mathrm{n}$ ' is linearly increasing, with respect to temperature.

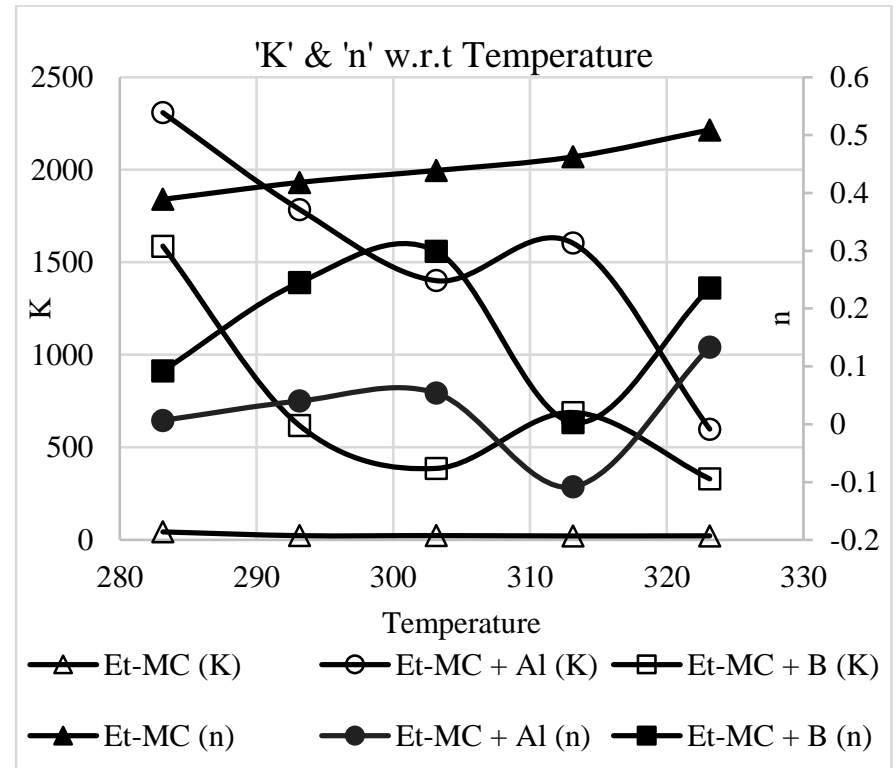

Figure 3.7. Variation of ' $\mathrm{K}$ ' and ' $\mathrm{n}$ ' as a function of temperature for all the gels

Thus, an empirical relation can be obtained. But for the other two gels Et-MC $+\mathrm{Al}$ and Et$\mathrm{MC}+\mathrm{B}$, initially up to $303.15 \mathrm{~K}$ a trend can be observed i.e. either increasing or decreasing, after which the behavior is unpredictable. Hence any empirical relation at temperature greater than $303.15 \mathrm{~K}$ for these two gels is unobtainable. This unreliability for these two gels is may be due to the presence of metal additives. A general trend observed for all the gels is that if the value of ' $K$ ' is increasing the corresponding value of ' $n$ ' is decreasing and vice versa. For detailed explanation of this trend, further studies need to be conducted to provide any justification of such behavior. For Et-MC + Al gel, ' $\mathrm{n}$ ' value at $313.15 \mathrm{~K}$ is negative which is as per with experimental data [15].

The convergence phenomena that have been observed for the gels can be explained by understanding the effect of shear rate on the gel structure. Gel is a continuous liquid enclosed by solid gellant matrix (formed due to weak intra-molecular and intermolecular interactions) which on application of higher shear rate tends to reconstruct/break and realign or disintegrate. According to De Vicente J. [17], the release of the entrapped liquid within, decreases the resistance to flow and consequently decreasing the apparent viscosity. As the base liquid for the investigated gels is Ethanol and Methylcellulose is the gelling agent, it seems that disintegration begins approximately between shear rate of $90 \mathrm{~s}-1$ and at $100 \mathrm{~s}-1$. The whole of the matrix must be disintegrated so that it starts to behave prominently like the pure base liquid. This is a Newtonian fluid hence the viscosity remains approximately constant at higher shear rates.

Generally, viscosity decrease with increase in temperature for most of the gel propellants and it is also observed for the test cases. As the temperature increases, the internal energy of Ethanol molecules increases and the surrounding Methylcellulose weak matrix bonds starts to break and reconstruct itself which leads to increase in fluidity of the gel [14]. As temperature keeps on increasing the gellant matrix become weaker and weaker and at certain stage it can no longer form a rigid matrix and phase separation occurs which is also observed by Varma M. et.al. [18] and by Sherman P. [19]. 


\section{Conclusions}

An empirical calculation with the proposed modified Power law can give a good estimation of apparent viscosity at varying temperature conditions considering some experimental data is available for such gels to obtain the reference parameters. For similar gels, it can be a useful relation to approximately predict the apparent viscosities at different temperatures for all the shear rates, which gives an additional advantage relative to the Power law. Presumably, temperature range of between freezing and transition point for a particular gel is the domain for this relation because phase or physical property will change beyond this domain. With the available experimental data, the predictions using the proposed modified Power law provided fairly good accuracy in predicting the apparent viscosity. The margin of disagreement between the experimental and empirically calculated values can be diminished by apprehending accurate reference parameters based on experimental results for varying temperature conditions. Further this model can be applied to simulate actual flow atomization and combustion model of gel propellants in varying temperature and shear stress conditions.

\section{Acknowledgements}

This research did not receive any specific grant from funding agencies in the public, commercial, or not-for-profit sectors.

\section{References}

[1]Schindler RC, Olson AM and Arnold CJ. A gelled propellant sustainer stage. In: AIAA Aerospace Design Conference, Irvine, CA, USA, (1992), pp.92-1122, AIAA.

[2]Brinker CJ and Scherer GW. Sol-Gel Science. Boston: Academic Press, Inc., (1990).

[3]Pinto PC, Ramsel J, Schmid K, Naumann KW, Niedermaier H, and Thumann A. Control characteristics of a gel propellant throttleable rocket motor. In: 5th European Conference For Aeronautics And Space Sciences, (2013), EUCASS.

[4]Naumann KW, Ciezki HK, Stierle R, Schmid K and Ramsel J. Rocket propulsion with gelled propellants for sounding rockets. In: 20th ESA Symposium on European Rocket and Balloon Programmes and Related Research, Hyère, France, SP-700, (2011), ESA.

[5]Ciezki HK, Kirchberger C, Stiefel A, Kröger P, Pinto PC, Ramsel J, Naumann KW, Hürttlen J, Schaller U, Imiolek A and Weiser V. Overview on the German gel propulsion technology activities: status 2017 and outlook. In: 7th European Conference For Aeronautics And Space Sciences, (2017), EUCASS.

[6]Canino $\mathrm{J}$ and Heister S. Contributions of orifice hydrodynamic instabilities to primary atomization. In: Atomization and Sprays, Begell House, Vol. 19, No. 1, (2009), pp. 91-102.

[7]Chojnacki K. Atomization studies of gelled liquids. In: 30th AIAA Joint Propulsion Conference, Indianapolis, Indiana, USA, (1994), AIAA.

[8]Heister S, Anderson W, Corvalan C, Campanella O, Lucht R, Pourpoint T, Sojka P, Son S, Meyer T, Schmidt D and Westmoreland P. Spray and combustion of gelled hypergolic propellants. Final report, Purdue University, (2014).

[9]Rahimi S and Natan B. Atomization characteristics of gel fuels. In: AIAA 34th Joint Propulsion Conference, (1998), pp. 98-3830, AIAA.

[10]Ferguson J and Kemblowski Z. Applied fluid rheology. Elsevier Science Publishing Co., Inc., New York, NY, (1991). 
[11]Jyoti BVS and Baek SW. Rheological characterization of hydrogen peroxide gel propellant. International Journal of Aeronautical \& Space Science (2014); 15(2) pp.112-121.

[12]Natan B and Rahimi S. The status of gel propellants in year 2000. In: Kuo KK and DeLuca L (eds) Combustion and Energetic Materials, Begell House, Boca Raton, (2000), pp.172-194.

[13]Natan B and Rahimi S. Thixotropic effect of inorganic gel fuels. Journal of Propulsion \& Power 2006; 16 (6).

[14]Cornelissen $\mathbf{J}$ and Waterman HI. Viscosity temperature relationship of liquids. Chemical Engineering Sciences (1955), 4, pp.288-246.

[15]Joyti BVS and Baek SW. Formulation and comparative study of rheological properties of loaded and unloaded ethanol-based gel propellants. Journal of Energetic Materials (2014), Taylor \& Francis.

[16]Madlener K. and Ciezki HK. Some aspects of rheological and flow characteristics of gel fuels with regard to propulsion application. In: 45th AIAA/ASME/SAE/ASEE Joint Propulsion Conference \& Exhibit, USA, (2009), AIAA/ASME/SAE/ASEE.

[17]De Vicente J. Polymer gel rheology and adhesion. In: Anne M. Grillet, Nicholas B Wyatt and Lindsey M Gloe. Rheology. InTech., Croatia, (2012).

[18]Varma M, Gupta BL and Munjal NL. Rheological studies on virgin and metalized unsymmetrical dimethyl hydrazine gelled systems. Propellants, Explosives, Pyrotechnics, (1986), pp.45- 52.

[19]Sherman P. Industrial rheology. London: Academic Press, (1970). 